\title{
التعذيب وعواقبه: متلازمة ما بعد التعذيب
}

ترجمة وإعداد: أ.د. سامر جميل رضوان

Samer Rudwan

https://orcid.org/0000-0002-8844-1307

فولكر فاوست

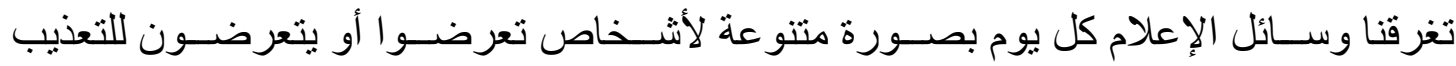

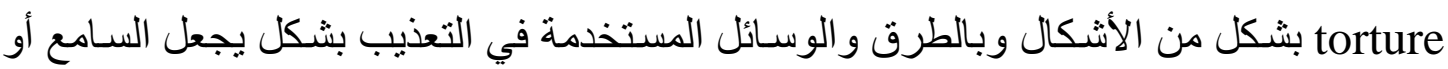

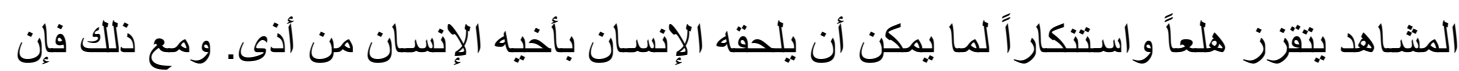

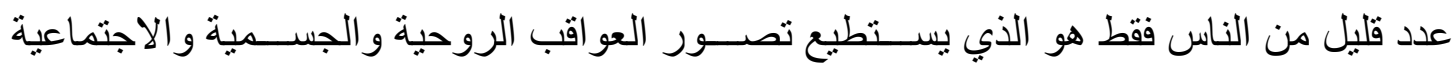
النفسية طويلة الأمد. فإذا ما نجا الإنســان من هذا التعذيب فإن الحياة تسـتمر بصـورة مشـحونة بالعذاب بشكل لا يقل عما كان الإنسان عليه تحت التعذيب. ذلك أن هدف وسائل التعذيب الحديثة

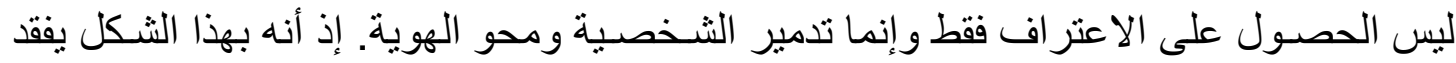
الإنسان أية قدرة على المقاومة.

وســـوف نقوم فيمـا يلي بالتعرض إلى الانتقاء فقط لبعض طرق التعذيب "الحديثة" و عو اقبها الجسدية، ومن ثم نتطرق للجر اح الروحية التي تتجلى من خلال الاستعداد الدائم للقلق، وظواهر

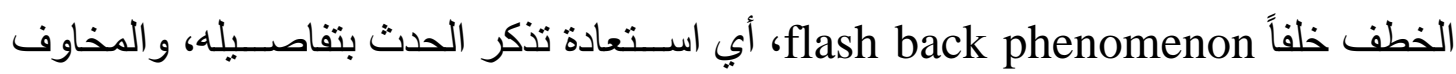
الر هابية المتجنبة للموقف، وحالة التوتر المسـتمرة وقهر الانثــال الفكري و الاكتئابية والمزاج المســتنار المتوتر وفقدان المبادرة و عدم القدرة على الهدوء و اضــــر ابات الانتباه و التركيز

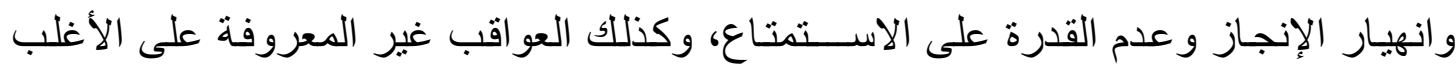

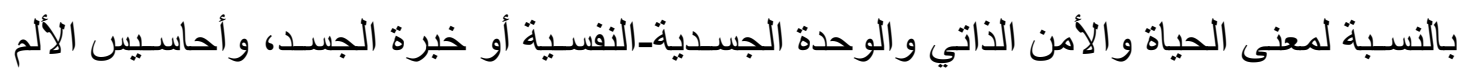
و الحياة الزوجية و المهنة...الخ. مع دخول العالم القرن الو احد و العشرين سـاحباً معهه صورة قاتمة من القرن العشرين زاد عليها

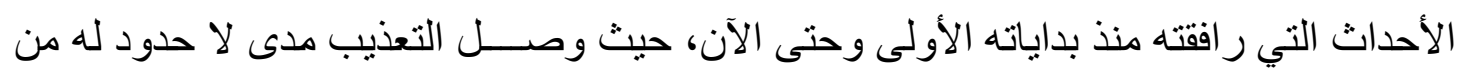
حيث الأشكال و الطرق، التي لم يكن كثير من الناس يعرف عنها شئه الان، هناً لو لم تسلط وسائل الإعلام 
بعض الضـوء على جزء مما يحدث في العالم قاطبة ســـواء على مســتوى الأفر اد و الجماعات

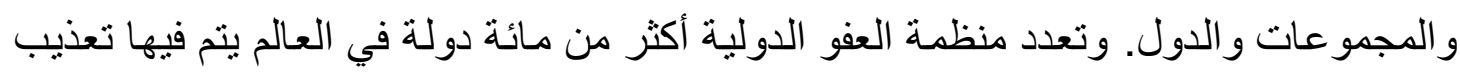

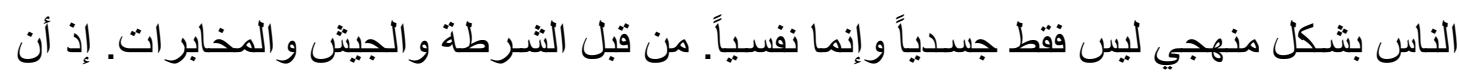

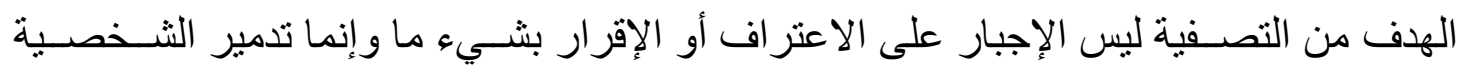

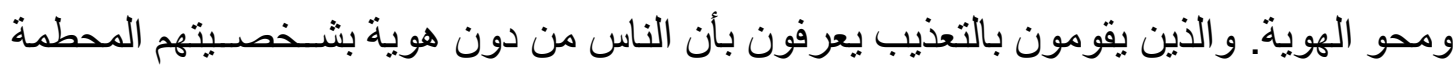
يفقدون قدرتهم على المقاومة دهما كان نوعها.

تحديد المفاهيم

تم في السـابق اســـذدام مصــلح متلازمة ما بعد التعذيب Post-torture-Syndrome. ويعد

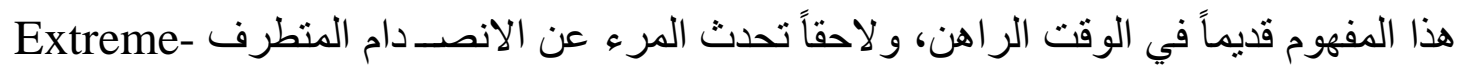

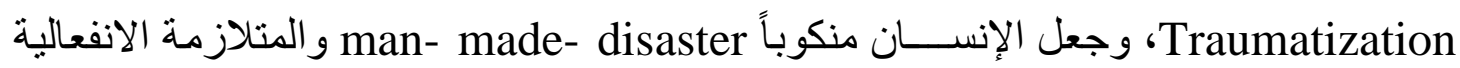

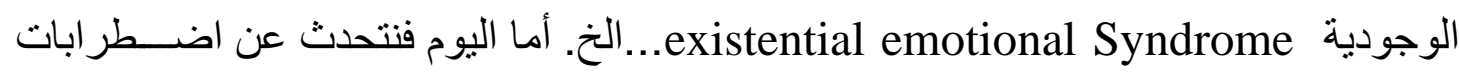

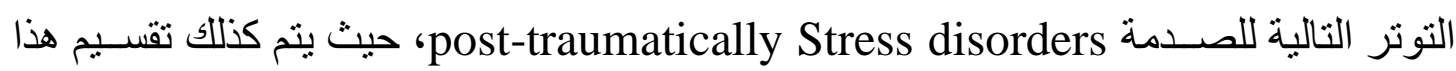

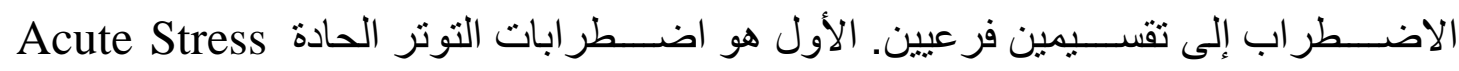

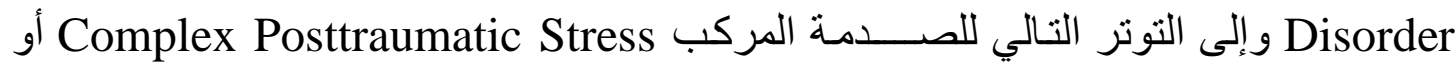
الثامل وذللك بسبب أن صدمة التعذيب لا تتوقف بعد التعذيب. ويتم تقسيم اضطر ابات التوتر التالية للصدمة إلى:

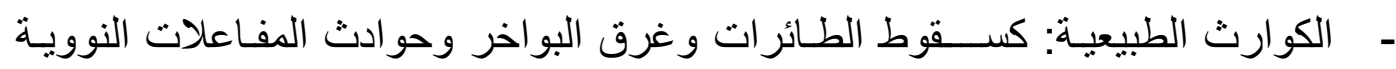

$$
\text { و الحو ادث الكيمائية...الخ. }
$$

- ـ الكوارث الطبيعية: كالز لازل و البر اكين والأعاصير و الفيضانات...الخ.

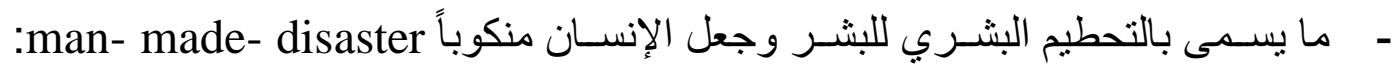
كالتعذيب و الاغتصاب و الاعتداء و السطو و الخطف و الأخذ كر هينة...الخ.

\section{هدف استراتيجية التعذيب "(لحديثة"} يتصرف الجلادون بشكل مخطط من أجل تحقيق هدفهم. فالإنهاك النفسي ينبخي أن يتم بالتدريج. و هذه العملية تكون محسوبة بدقة، يتم تتفيذها بدم بارد وحسب السمات الفردية للضحية المعنية. إذ ليس من المفيد البدء مباثرة بالإجر اءات الأقسى. فعلى المرء أن يترك للضحية الوقت الكافي

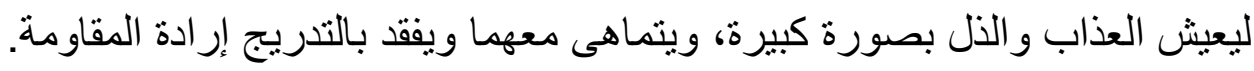


على الضحية أن يفقد كل سند داخلي وكل إحساس بذاته بشكل لا حول له ولا وقوة فيه، عليه أن

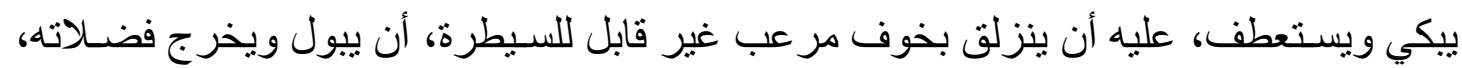

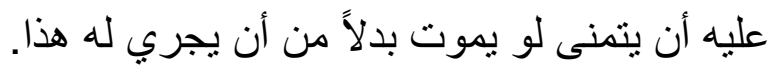

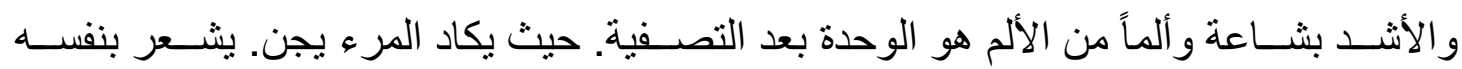

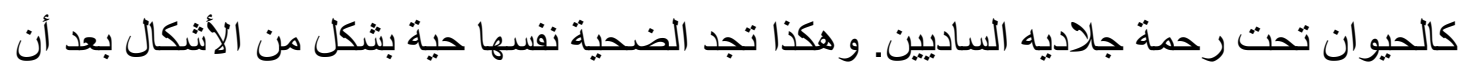
يتم إطلاق سر احها، إلا أنها محطمة نفسياً. و هذا هو هدف التعذيب "الحديث".

\section{طرق التعذيب} طرق التعذيب قديمة قدم الإنسـانية وينم تجديدها باسـتمر ار و إكمالها بطرق "جديدة". فإلى جانب

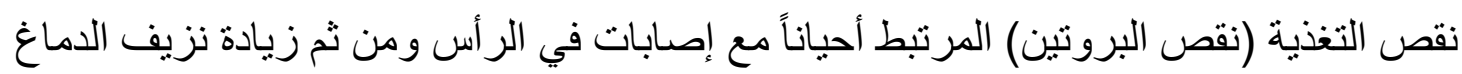

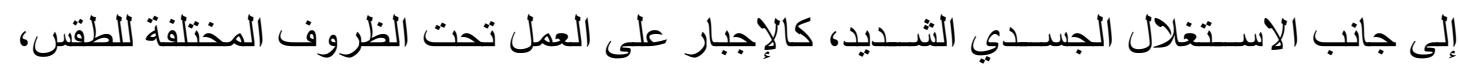

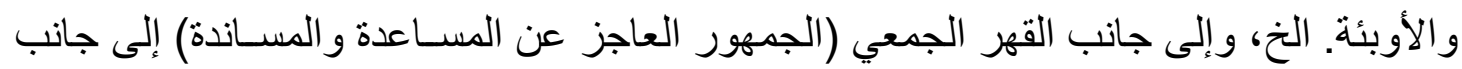

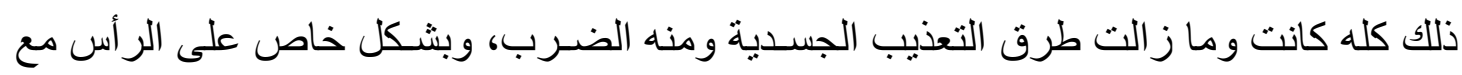
آثار جدية أحياناً كفقدان الوعي وكسـر العظام و النزيف و الدم في البول و الجر اح المفتوحة من ثم

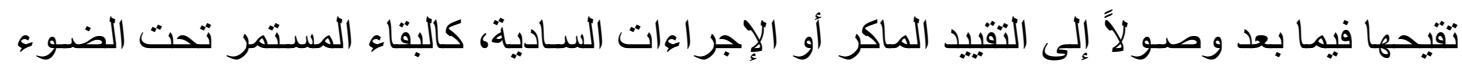

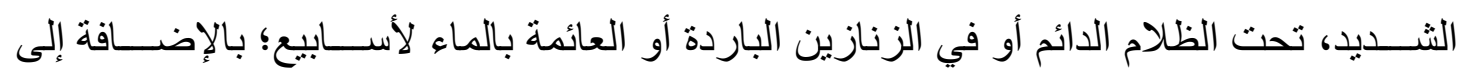
الدبابيس تحت الأظافر والحرق بالسجائر و التغطيس في الماء البارد ولي المفاصل...الخ.

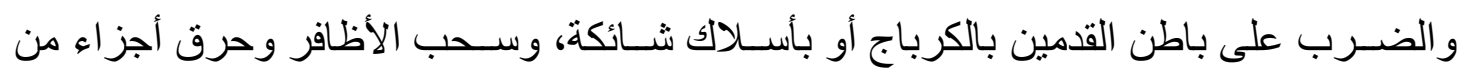

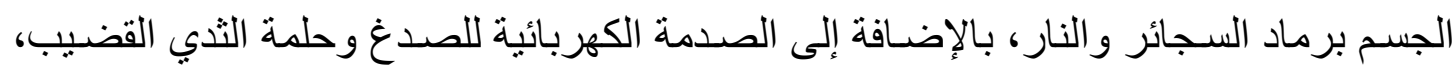
و السجن الإفر ادي في زنز انة عازلة للصوت و الاغتصاب، حتى للرجال، و الإيهام بإطلاق النار ، وكنلك الحث المخفي أو الواضح على الهربه عالهربه من أجل التمكن فيما بعد من إطلاق النار بالفعل.

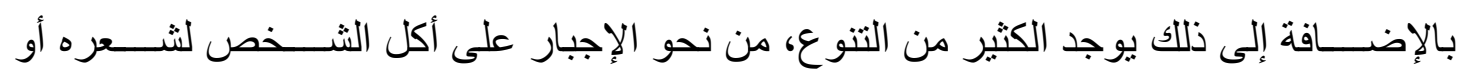

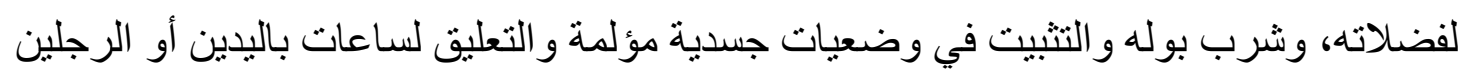

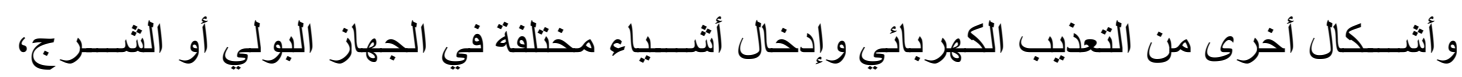
و التبول في الفم...الخ. ومن الجدير بالملاحظة تللك الأسـماء السـادية التي تطلق على طرق التعذيب المنفردة. فالضـرب

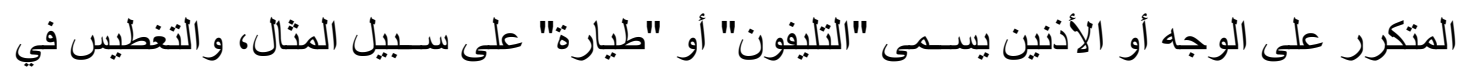

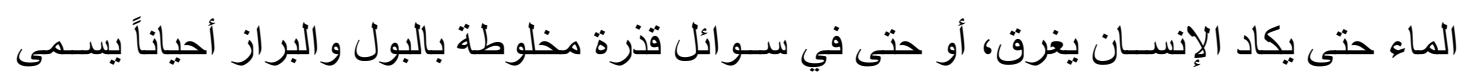


"الغو اصــــة"، وربط اليدين و القدمين على الظهر و التعليق بعدئذ في هذه الوضـــعية يســمى "الأرجوحة" أو "أرجوحة الببغاء" أو "الثبح"...الخ. كما يشكل سماع الصر اخ الحقيقي أو المفتعل لسجناء آخرين و الذي يستخدم كذلك كسـلاح تدمير هادف، إنهاكاً واسـتنز افاً حاداً. و على المدى البعيد يعذب التهديد الدائم بالموت، وكون الإنســان تحت رحمـة إر ادة تـدمير لا ترحم من دون مبرر ودون ارتكـاب أي ذنب مهمـا كـان نوعـه. فالبعض يخفف عنه إذا ما اسـطاع أن يعزو هذا الأمر لذنب ارتكبه، ولكن بالنسـبة للكثيرين فإن غياب الحكمة الإيديولوجية لهذه المعاناة، التي نجدها على الأقل لدى الضـحايا من السـياسيين أو المتدينين، أو المقاومين الذين يقاومون الاحتلال، تسبب رعباً إضافياً. و الفاجعة الكبيرة هي اليقين بأن كل هذا غير محدود زمنياً و إنما ســوف ينتهي باحتمالية كبيرة بتدمير جســي، يتمثل في خوف لا ينتهي، ويتحول في النهاية إلى الاشـتياق للموت. وهكذا يجد المرء نفسه فرحاً بالعذاب اليومي الذي يجتازه حياً على الأقل. و ما يسـتنزف بشـكل خاص على المدى البعيد هو أن كل ذلك يحدث من دون تخفيف، باسـتنثاء الاستر احات القصيرة المذكورة التي تستخدم كفو اصل خوف هادفة. وهكذا لا توجد للضحايا أية إمكانية لعمل شيء على أدنى مستوى حيوي على الأقل والاستجابة لشيء ما.

لا توجد در اســات مبنية حول طبيعة الجلادين، يمكن الحصـــول عليها من جماعات كبيرة من الجلادين. وما يتوفر بعض التوصـيفات الفردية. فبعضــهم يختفي وبعضــهم الآخر يلقى القبض عليه ويحاكم من دون أن يسـمع عن ذلك في وسـائل الإعلام. و عدد ليس بالقليل منهم يظل غير ملفتاً للنظر و أحياناً يلفت النظر بشــكل إيجابي، كأن يكون أباً طيباً، أو جار اً لطيفاً، أو موظف غير ملفت للنظر ...الخ. و التفاصـيل سـتقودنا بعيداً عن الموضـوع، إلا أنه لا بد من الإثــارة إلى مظهرين:

1 - من المهم أن نعرف أنه لا يوجد جلادون قســاة فحسـب و إنما هناك جلادين "ودودين" أيضـاً، و الذي يبدو أنه يعتدي بشفقة من أجل مسـاعدة الضـحية، ويبدي التفهم له، سـواء بالكلمات أو بالأفعال. إلا أن كلهم يتبعون الهدف نفسـهـ. أي تدمير الضــحية في تكيفه، و اسـتبعاده من الجماعة وذلك بأن تســلب منه ثقته في الإنســانية ويصــبح شـــاكاً في المجتمع. على المعني أن بعاني من الثـك و القلق والثـعور بالذل و الصــ ورفض الذات حتى آخر يوم في حياته. 
r- من منظور تنظيمي لابد من الإثــــارة إلى أنه يتم تبادل المعارف حول طرق التعذيب

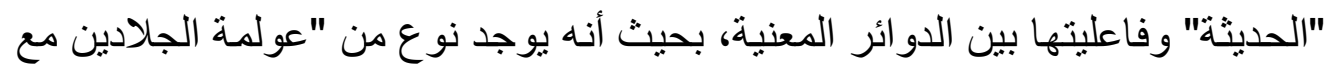

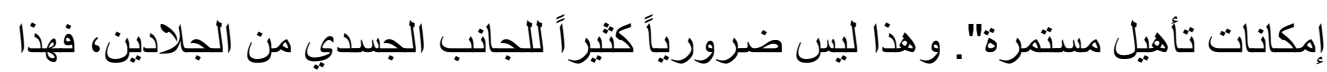

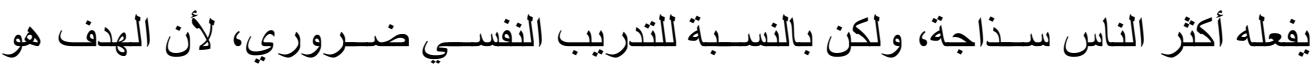
تحطيم نفسية الضحية من أجل تحقيق تأثير مدمر طو ال الحياة.

العواقب الجسدية للتعذيب

organic-traumatic العو اقب الجسدية للتعذيب إما أن تكون من طبيعة عضوية صادمة' Nature النفسية الناجمة عن التعذيب على سبيل المثال، تتجلى من خلال الأعر اض الجسمية، التي لا لا لالهن يكون لها سبباً جسمياً قابلاً للبرهان ولكن هذا لا يغير من الأسباب و العو اقب. ليس من النادر أن يتحول الجسدي إلى نفسي و العكس. ومن أكثر الأعر اض ملاحظة الصداع و الثكاوى القلبية وضيق التنفس و الدوار و اضطر ابات

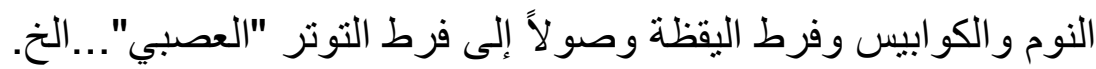

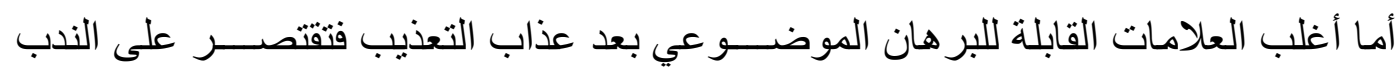
وضـف الحركة و إعاقات المشـي وأضـرار الأسـنان و إصـابات طبلة الأذن و العيون. وغالباً

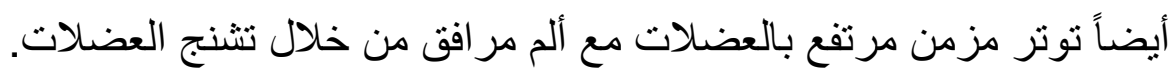

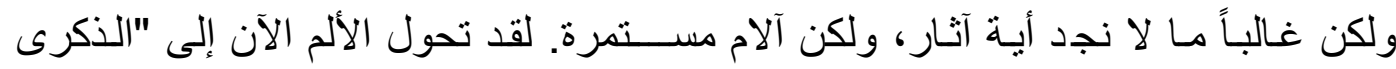

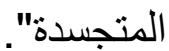

العواقب النفسية للتعذيب فيما يلي عرض مختصـر لأهم أعر اض التعذيب وذللك على المسـتوبين النفسـي الجســـي

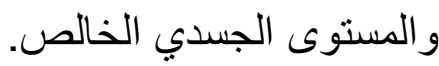
( ) الأعراض النفسية الجسمية الجندية من العو اقب النفسية الجسدية القابلة للتفسير للتعذيب يمكن تعداد على سبيل المثال: - - مالات التعب: وتتر افق مع استعداد متز ايد للمرض وبشكل خاص العدوى.

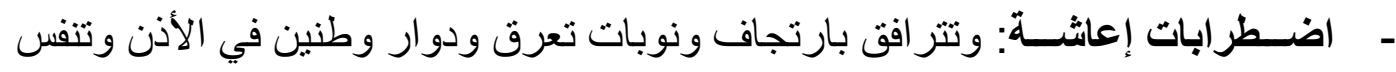
لاهث:...الخ. 


$$
\text { - - اضطرابات نوم: ونتر افق مع كو ابيس وصر اخ ليلي. }
$$

- شكاوى قلبية: وتر افق مع تسرع في القلب و عثرة فيه ووخز وضغ وضغط في في القلب وضغط

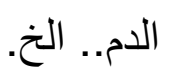

- مشــاعر ضـنط: وتتمركز في الصـدر و الثـعور بالغصـة في الرقبة (اضـطر ابات بلع،

$$
\text { ومشاعر بالضيق) وضيق التنفس...الخ. }
$$

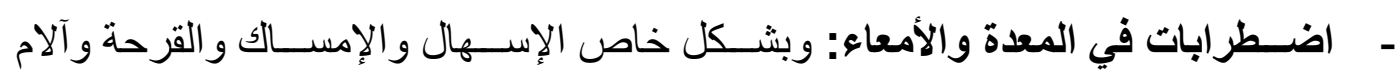

$$
\text { المر ارة و البو اسبر واضطر ابات المثانة...الخ. }
$$

- آلام من كل الأنواع وفي كل مكان: صداع و آلام ظهر وكتفين ومفاصل ولدى النساء آلام

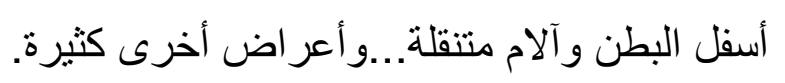

- تثـنج العضلات: في دفاصل الفك و آلام في قفا الر أس (القلق في القفا)، ومجال الكتفين

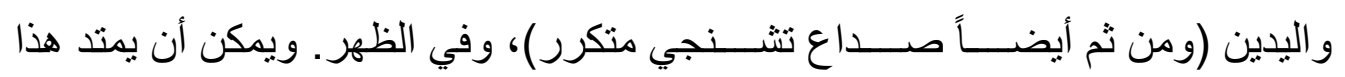

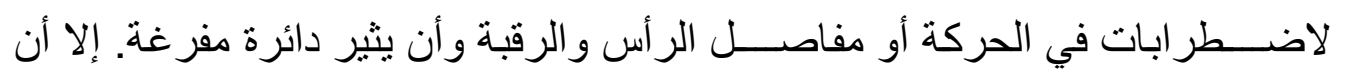

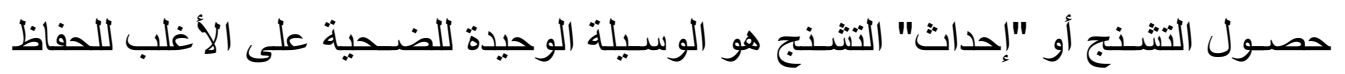

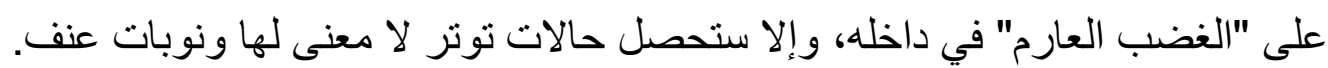

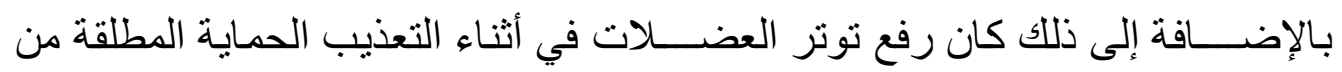
الضربات. وهذا التوتر بستمر بالتأثير وكأن التعذيب مستمر للأبد.

\section{r r عواقب التعذيب القابلة للقياس الموضوعي} من بين أكثر العو اقب التي تنــتمر لفترة طويلـة أو حتى طوال الحيـاة القـابلـة للتحديد الموضو عي objectivize طبقاً لطريقة التعذيب يمكن تعداد:

$$
\text { - }
$$

- ثقب طبلة الأذن من خلال الضـــرب باليدين على الأذنين مع تميز الثقب كما يحدث من

$$
\text { بصدمة الانفجار؛ }
$$

- ندب مطابقة من خلال الوخز و التقييد (على مفصــلي اليدين على ســـيل المثال)، ومن

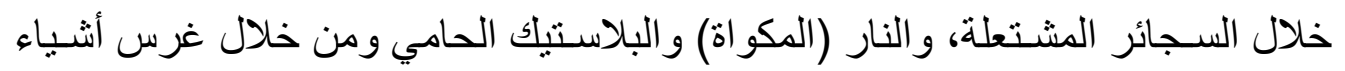

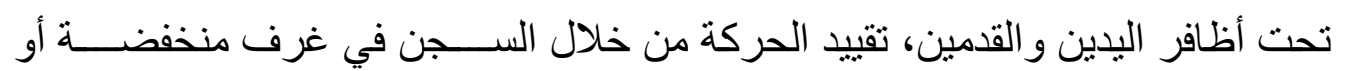

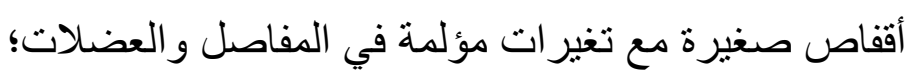


- إصـابات في الر أس بعد التعليق (و الر أس للأسـل أيضــاً) مع إسـقاط مفاجئ و الضــرب

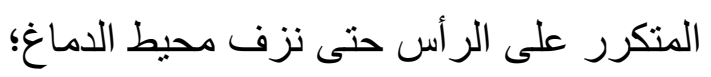

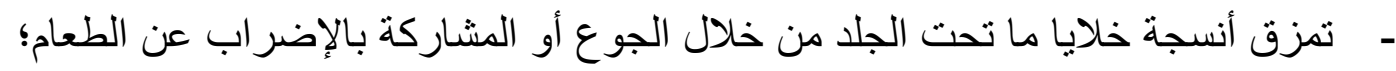

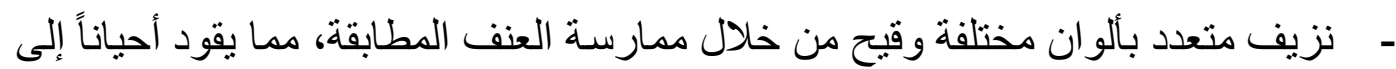
ضرورة إجراء ديلزة، بسبب وجود الكثير من البروتين في الكليتين.

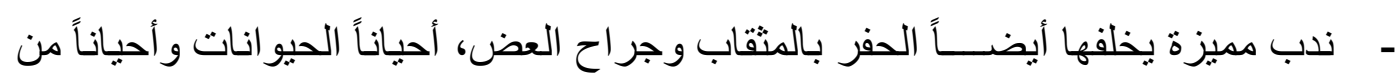
الجلاد نفسه، حيث يتم رش الملح على الجرح كذلك.

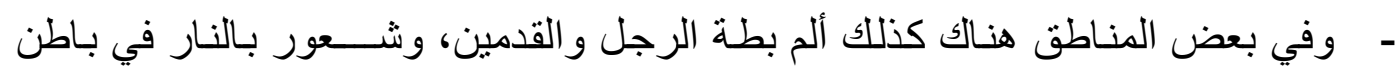

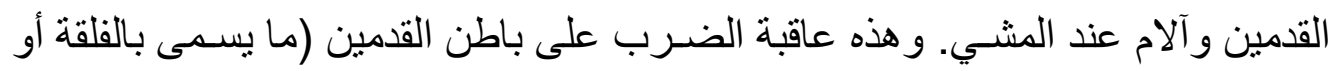

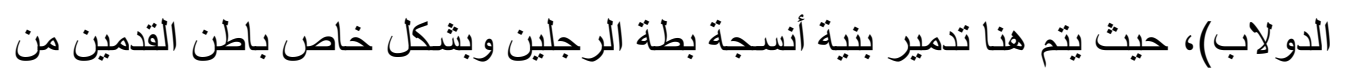

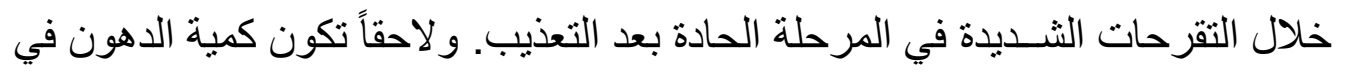

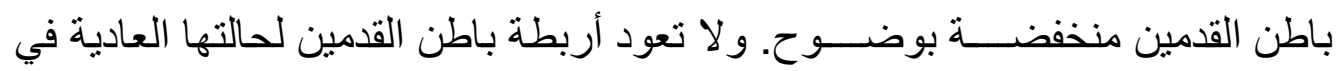
التوتر أو الثد، إبهام القدم يصبح ممطوطاً.

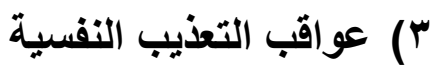

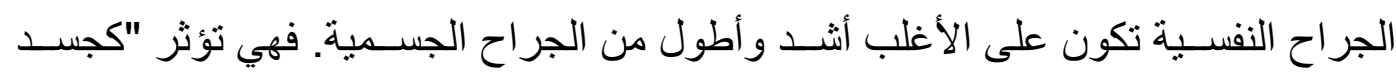

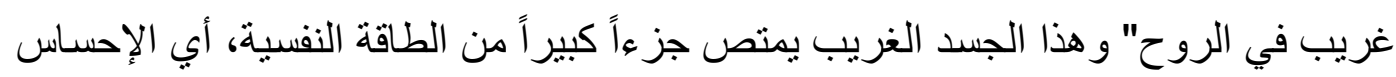

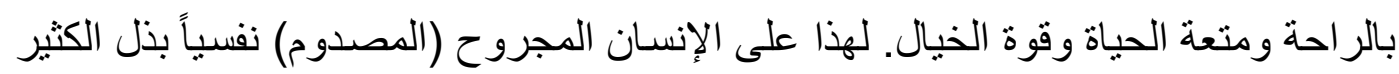

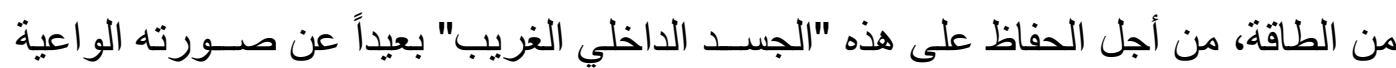

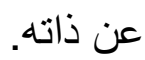
أما غالبية الثكاوى تكون في المجال الروحي و النفسي الاجتماعي والنفسي الجسدي فهي: - - القابلية السريعة للإنهاك النفسي-الجسدي؛ - - متراجع القدرة على التذكر والانتباه، - عدم استقرار عاطفي وصولاً إلى انفجار البكاء غير المسيطر عليه، -

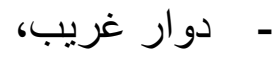

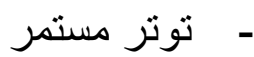


- عدم هدوء وتوتر و عصبية، يضاف إلى ذلك الاستثارة و العدو انية، - - حالات قلق من جميع الأشكال، - - ماب يطفو بحرية، أي ذكريات موجهة بشكل قسري لأمور معينة، - - فقدان الهدوء عدم استقرار انفعالي وحالات من التعكر الاكتئابي، - - الميل للانشغال الفكري المعند،

- مقرة مرتفعة بشكل شاذ على التذكر ، ولكن لمشاهد مر عبة من الملاحقة.

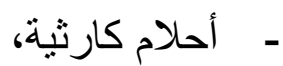
- - الثعور بالتدهور والانحطاط، وفقدان القيمة والعزلة. -

ومن الســـات الأســاســية المميزة إلى حد ما هنا هي اضـــــــابـات التذكر أو فجوات التذكر

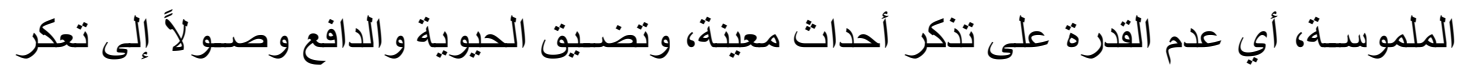

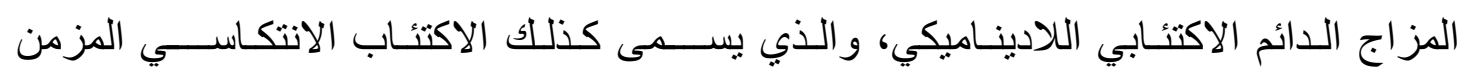
chronically reactive Depression هذا الثكل من الاكتئاب يتضمن مثير ات ملموسة لاكتئاب دائم.

\section{؛ (العواقب البين إنسانية}

غالباً ما تقود القدرة المنخفضــة على الإدارة الفاعلة للحياة بثكل خاص إلى التتـتت الثـديد

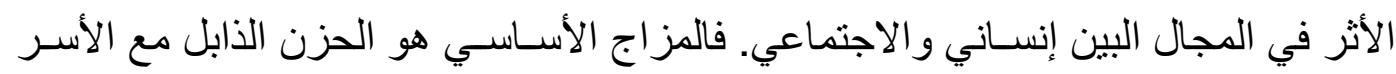

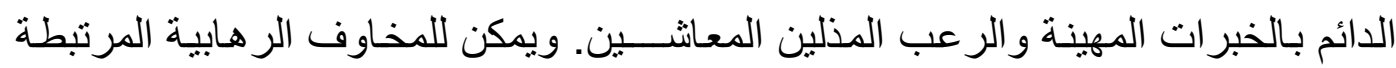
بالموقف (مخاوف قهرية) المتر افقة مع هلع فريد، حتى من الأحداث الحيادية أن تكون معيقة

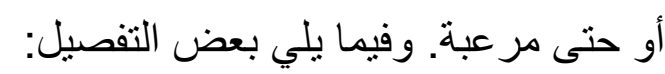

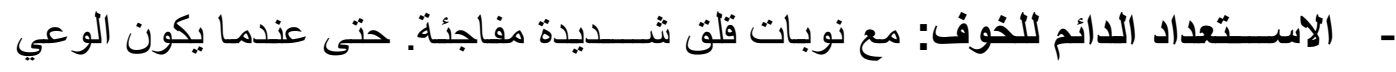
الصاحي يعرف أنه متحرر من القلق، فإنه يمكن للقلق أن ينفجر في الكو ابيس.

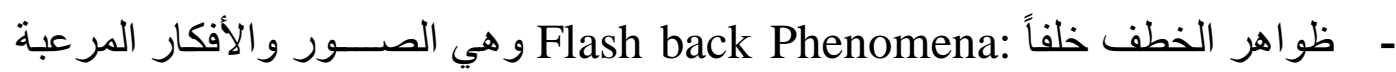
التي تظهر فجأة وبثـــكل اقتحامي، بما يثــــه النوبات من مو اقف التعذيب الماضـــية،

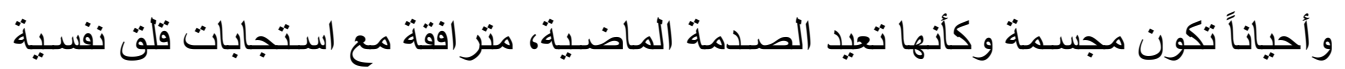
وجســدية بشـــل خاص مطابقة (الارتجاف، نوبات تعرق، قلق، حالات عدم هدو وتوتر ...الخ). 
- مخاوف رهابيه مرتبطة بالموقف: كالخوف من لابسـي الزي العسـكري أو ما يســى

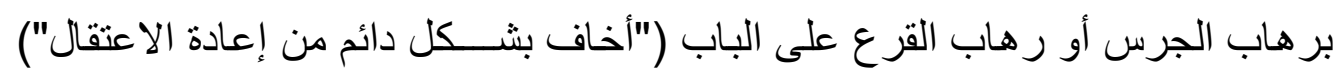
على سبيل المثال، وتنتثار هذه المخاوف أحياناً من خلال رائحة العرق و القرقعة (تلقيم

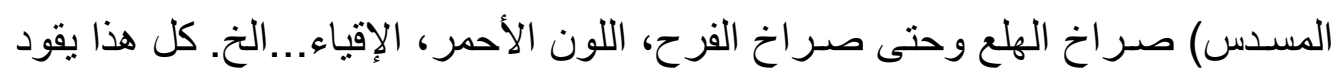

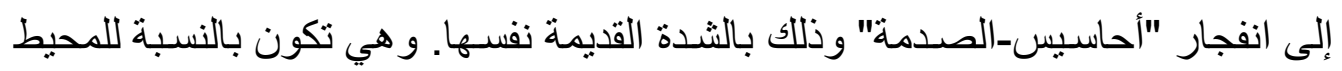
مفاجئة كلية وغير مفهومة بالطبع. و غالباً ما يرتبط هذا مع قابلية للهلع مر عبة وغريبة

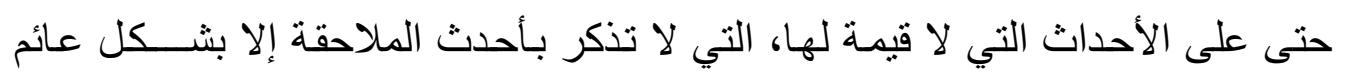
(أصوات الألعاب النارية، منبه سيارة، أصوات المحركات، أصوات الصعات الصعود أو الهبوط

$$
\text { على الدرج، القرع على الباب...الخ). }
$$

وتجبر المخاوف القهريـة المحددة على تجنب التجمعات الإنســـانية الكبيرة والدخول للسينما و المسرح أو إذا ما ذهب الثخص هناك فلا بد أن يجلس في مكان متطرف يؤمن الإنس

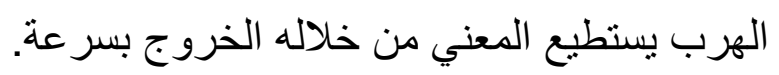

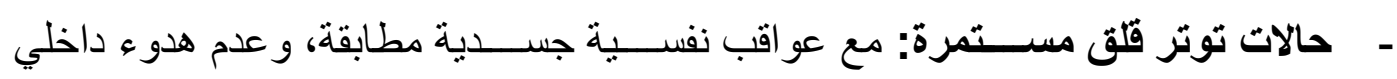
و اضطر اب وقلق ووضعية جسدية مميز. - قهر الانثـغال الفكري مع دوران معذب للأفكار: (وأحيانا مع دقة تذكر تصـويرية دقيقة للمشاهد المر هقة). الاكتئابية: الاكتئابية لا تعني الاكتئاب، و إنما فقدان القوى الحيوية والاســـتعداد المزمن

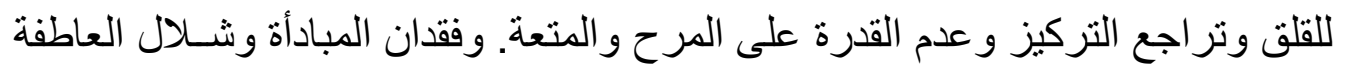
و الانسحاب الإعر اض عن عالم المشاعر الذاتي، عدم القدرة على الإحساس بالذات لهذا يبدو المعنيون وكأنهم محترقين وفار غين ومتبلدين.

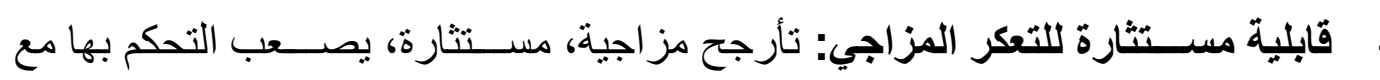

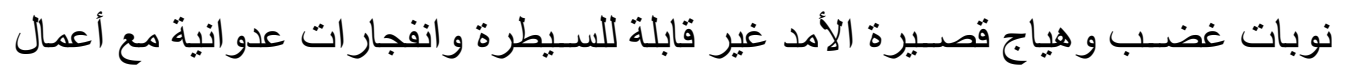

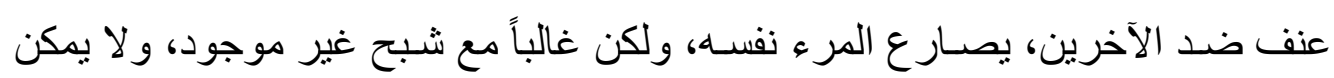
تذكر أي شيء بعد ذللك، وكذلك ضرب نفسه، مع كل ما يحمله ذللك من خطر أذى الذات

$$
\text { أو حتى الانتحار. }
$$

- الثـلل العاطفي: لا يعود أي شــيء يمس المشــاعر، لا الأخبار السـيئة و لا الجيدة. تبلد كامل لكل المشاعر وصو لاً إلى الفراغ الداخلي (الموت الداخلي). 


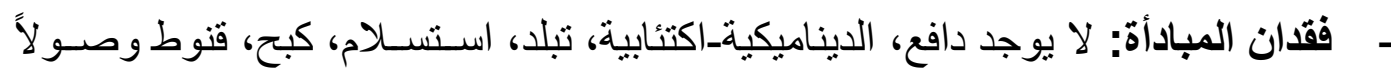

إلى انسحاب لا مبالي apathy وخطر الوحدة و الانعز ال (انسحاب كئيب).

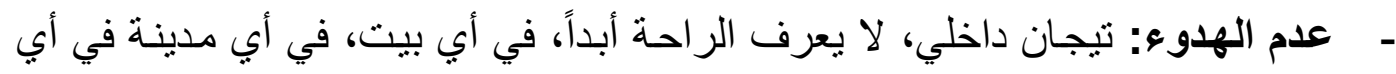

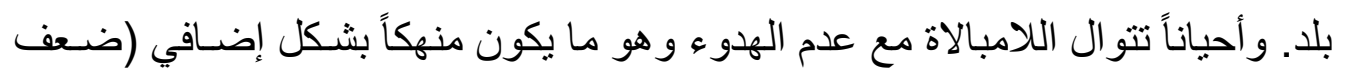
مستثار و لامبالاة مدفوعة). - - تداعي التركيز وتراجع الإنجاز: اضطر ابات انتباه وتركيز ونسيان وسر عة في الإنهاك بالتر افق مع نقص في الإنجاز على المستوى الروحي والبين إنسـاني وأخيراً في المجال الجسدي و المهني.

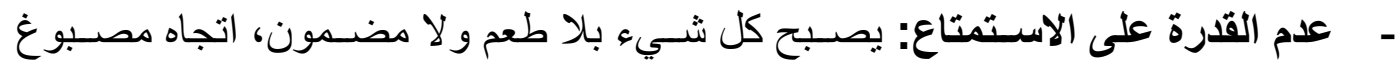
بالسلبية مع حلقة مرفقة مطابقة. - - ســؤال المعنى والثقة بالنفس: يعد عامل الإرهاق ذبي العو اقب طويلة الأمد عاملاً مهماً

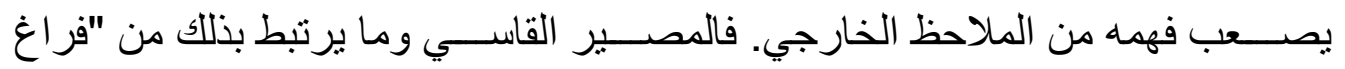

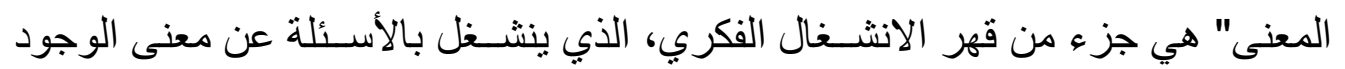

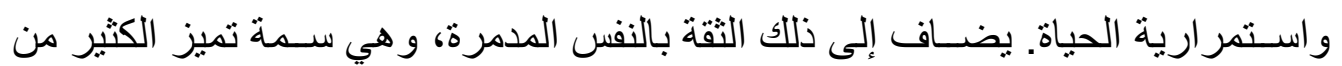

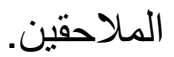

مظاهر خاصة للأثخاص الأين تعرضوا للتعذيب

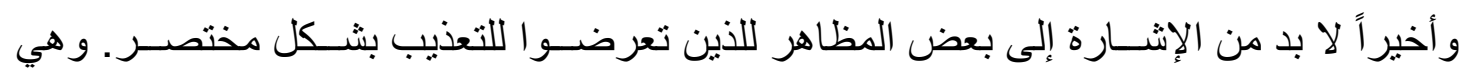

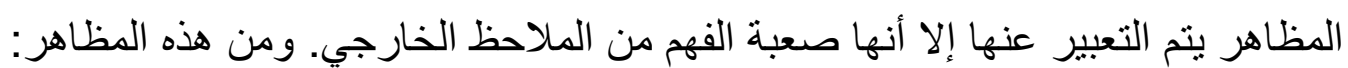

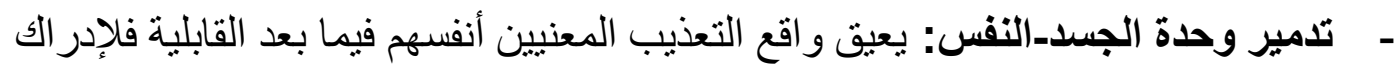
أو الفهم والانعكاس في التفكير وفي الفهم والتقويم لأن أساس جوهر الثخصية قد اهتز. فمن خلال التعذيب تضــطرب وحدة الجســـــ النفس بثـــل عميق. فلا يعود المعنيون

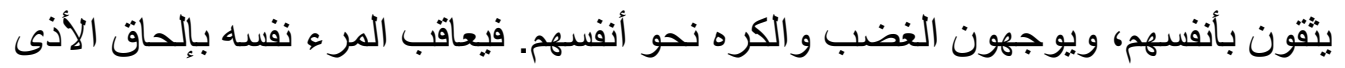

$$
\text { و عدم الإحساس بجسده ويرفضه كجسد غريب عنه. }
$$

- الخصائص النفسية للإحساس بالألم: تعزز أحاسيس الألم الروحية، أي النفسية الجسدية

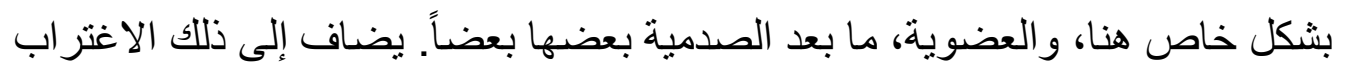

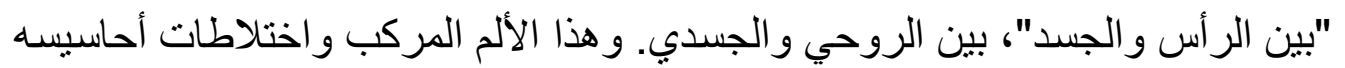
التي لا تحصى تحت عتبة الألم، مع عدم وجود خسارة عضوية، تعاش كوحش مفترس. 
ويرتفع من خلال ذلك خطر سلوك تجنب وخيم العو اقب، وهي إحدى السمات الرئيسية

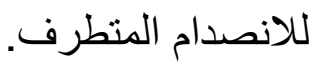

إذ أن من يثـعر بالألم لا يسـنطيع عندئذ التفكير والاسـتنتاج بوضـوح و لا يسـنطيع في

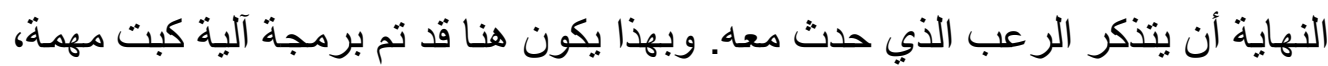

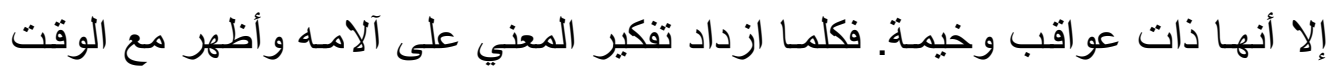
سلوك ألم متعدد و اضح بما في ذلك توقعات الألم أيضاً كان ضمان عمل الكبان الكبت أكبر. - العواقب على الثريك: إذا ما تم تعذيب الثريكين فإن هذا سيدمر العلاقة. إذ تحصل هنا

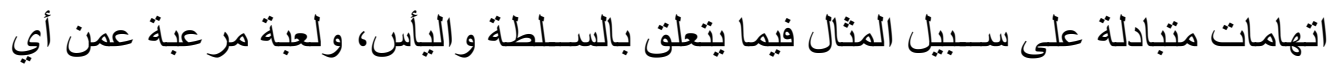
منهما عانى من الرعب أكثر، و عزو طرق التعذيب للآخر، ومطالب متبادلة غير قابلة للتحقيق نحو التفهم والرعاية وفقدان القدرة على الحب الذي يحاول كلاهما الهطالبة به. وغالباً ما تكون النتيجة الانفصال أو الطلاق. - اضـطراب خبرة الجســ: لا يعود ضـحايا التعذيب يشـعرون باتحادهم مع جسـدهم. إنهم

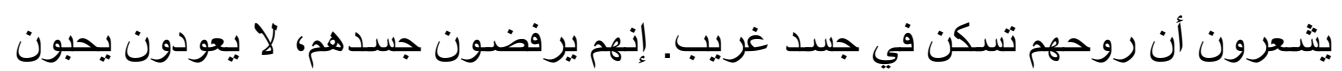

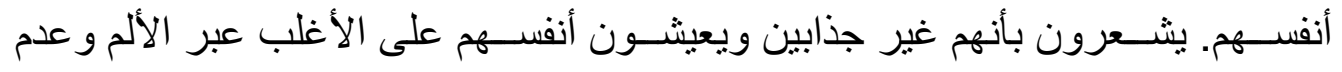
الهدوء و الارتجاف، أي عبر السكة الجسدية التي خرجت عن مسار ها. إنهم برون الندب

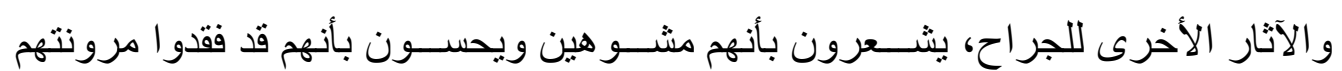
الحركية وقوتهم وقوة جذبهم.

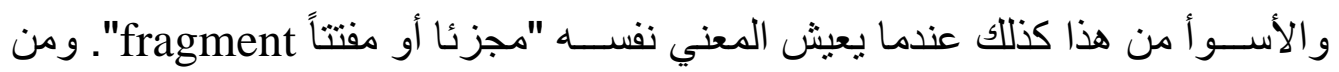
خلال ذلك يمكن أن يحصل انقسام انفعالي لأجز اء الجسد. فلا تعود الارتباطات الطبيعية

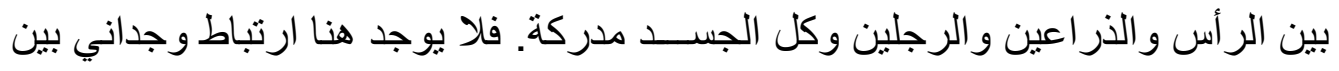

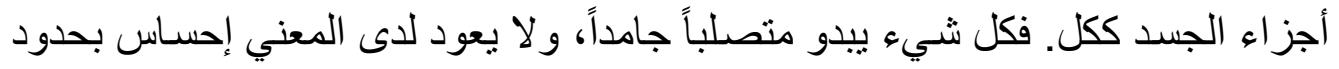

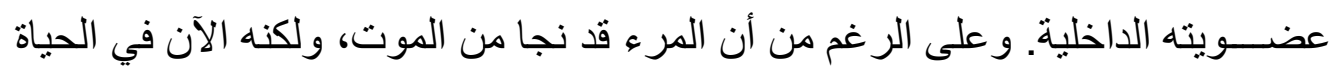
كالميت.

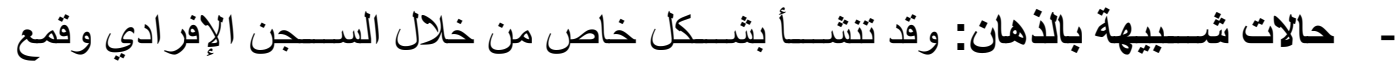
الإدر اكات الحسـية. و عليه يمكن للعينين المعصـوبتين في أثناء وبعد التعذيب أن تســـل

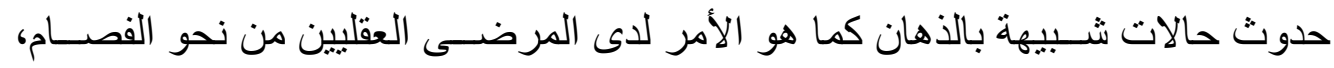

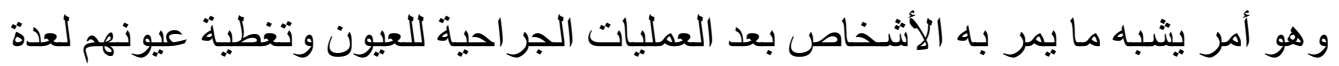


ـ طرق التعذيب الخادشــة للعياء: وهي تللك الطرق التي لا تخدم تحقيق اعتر اف كثيراً

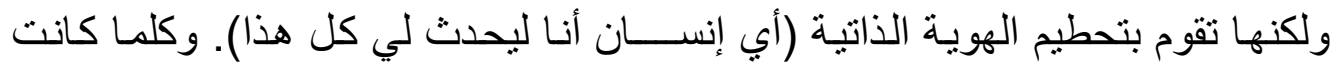

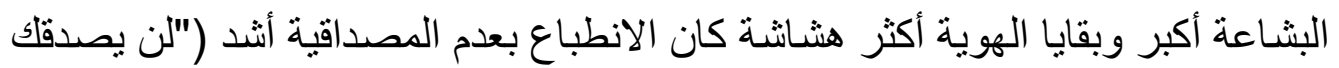

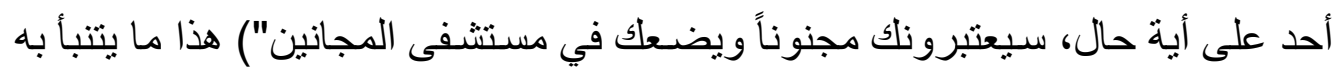

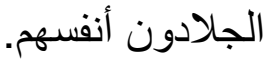
المتطرف (فرط التهوية Hyperventilation أو ما يسمى باللاهاث المرضسي)، ونتيجة للقلق والألم و أحياناً من خلال التأثير ات العنيفة على الر أس و الظهر. ـ متلازمة النقص: من خلال نقص البروتين و الفيتامينات و الحريرات مع الممارســـات

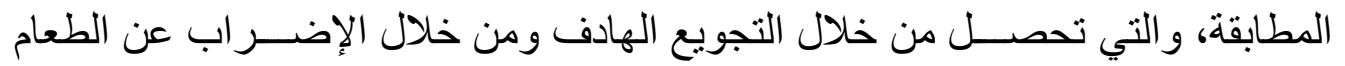
يحدث نقص في التخذية. و غالباً ما تكون العو اقب من طبيعة عضولة، ولكن لكن أيضاً نفسية

و عقلية (آفات دماغية).

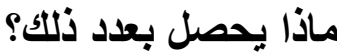

تعد فترة التعذيب مر هقة بثـــكل متطرف، ولكنها لا تقل فيما بعد إرهاقاً كما تثبت ذلك العو اقب النفسـية و الجسـية و الاجتماعية النفسـية. ولكن هناك إرهاصـات أخرى أيضــاً وإهانات و إذلال وإحباط ومن ثم انصدامات أخرى.

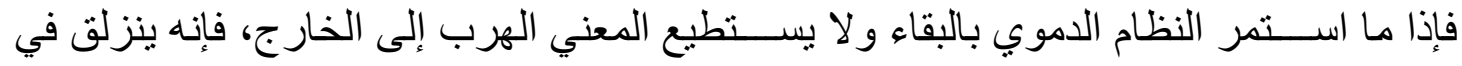

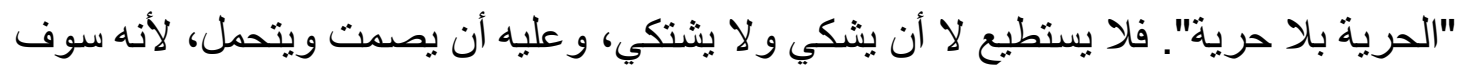

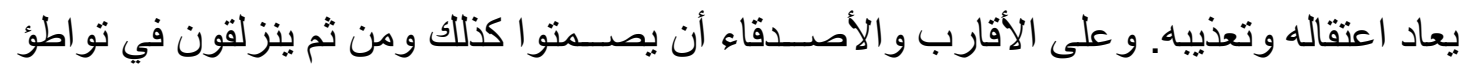

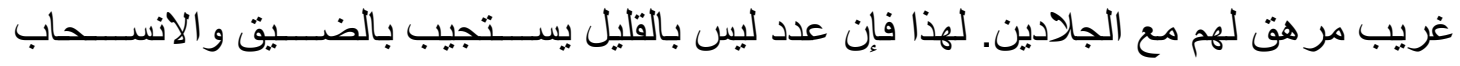
و الثكاوى المبطنة أو العدو انية.

فإذا ما استطاع الضحية الهرب للخارج/ فإنه يصبح لاجئًا. وهو ما يحمل معه مشكلات من نوع خاص، كما يعلم كل من يتعامل مع مثل هذه الحالات.

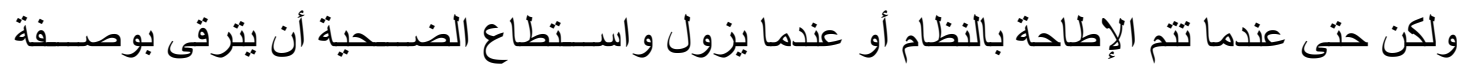

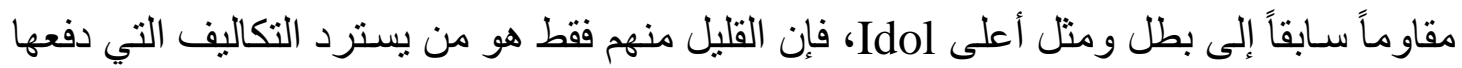
في ســيل ذلك. فغالباً ما تحتل مشـــلات أخرى الأولوية، كإعادة البناء و الدمقرطة و التحالفات

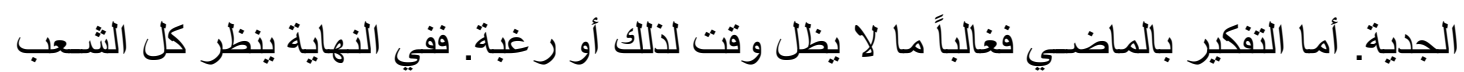


لنفسـهـ على أنه ضـــة. ويكون موقف الناس تجاه المناضـلين السـابقين مزدوجاً على الأغلب. ويبدو أن هذا الأمر يتشـابه في كل الأمم. فهو في النهاية يذكر بما كان وبما تكيف الإنسـان معها،

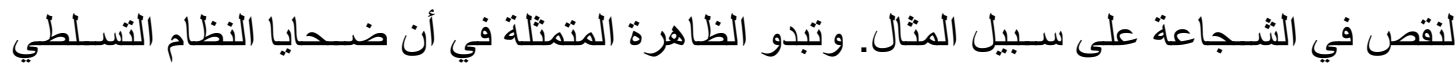
القمعي غبر محبوبين ظاهرة عامة، لأنهم يحافظون على ضمير الغالبية الصامتة صاحياً.

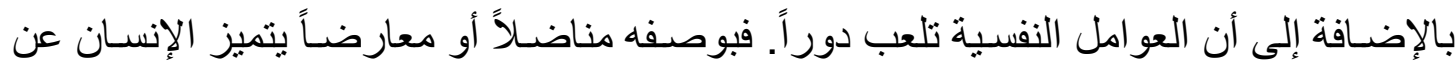

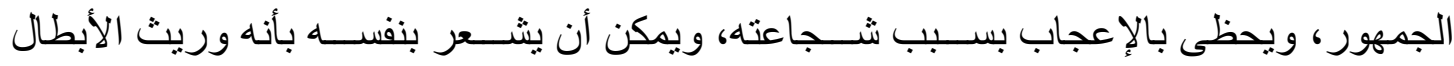
التاريخيين. و هذا ما يمنحه القوة و الهوية. ولكن بعد ســقوط النظام يبدأ الانقلاب، فتســقط هذه الهالة ويصبح الإنسان جز أ من الجمهور الكبير. بعد ذللك لا يحصـل المرء في المجتمع -الذي ربما أصــبح مجتمعاً تعددياً. على حقه إلا إذا نظم

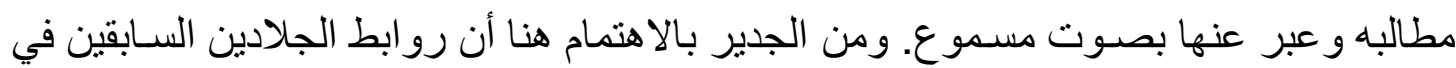

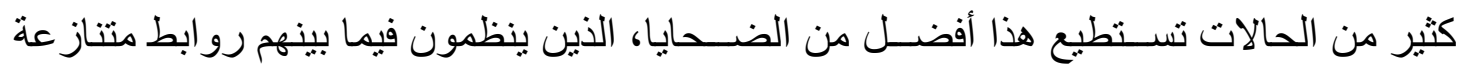

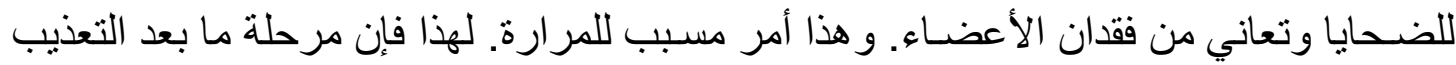

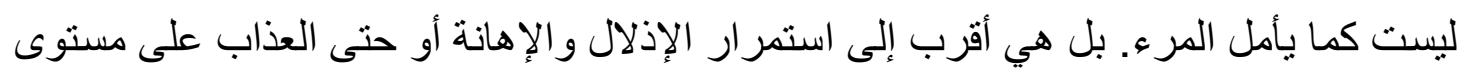

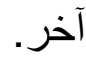

ويعد عدم الاعتراف بالتعذيب وعو اقبه انصـــام متجدد، حيث يكون المجتمع في عيون المعنيين

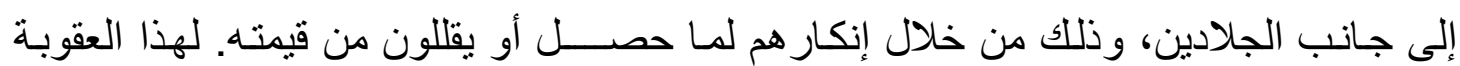
بالسجن لجلادي النظام السـابق، تثثر لدى الضـايا الناجين ردود أفعال شـديدة. فالحكم القضـائي بالسجن هو جزء من العدالة ورد الاعتبار. ولكن حتى العقوبة بالسجن مبررة قانونباً، مهما كانت

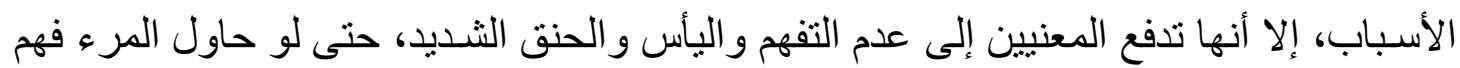
الأمر: (لقد أردنا العدالة فحصلنا على دولة القانون"). و على ما يبدو فلا وجود للعدالة المطلقة. فعملية التظلب على الكثير من الصدمات ليست مستقلة عن المآســي الإنسـانية، فالجو الاجتماعي يذهب باتجاه الكبت و الإنكار، كي يعود الهدو ثنانية.

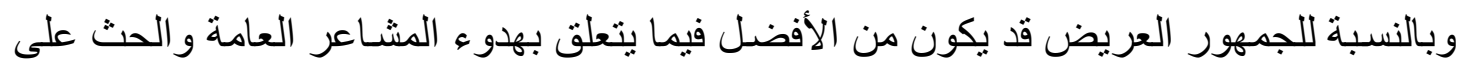
إعادة البناء. أما بالنسبة للمعنيين فإن ذلك يظل شوكة في الحلق. 
على الرغم من أن العلاج عبارة عن مغامرة مر هقة إلا أنه لابد من تحقيق الأســاس التي يحفظ

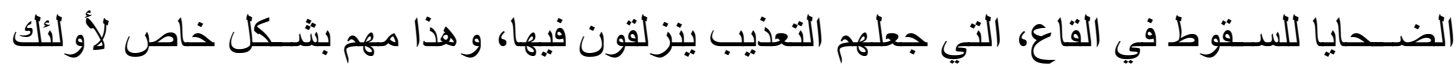

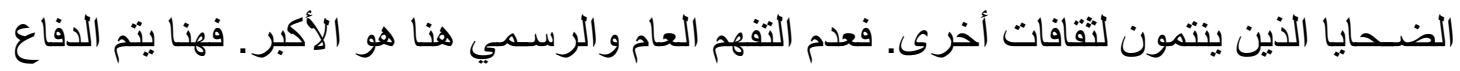

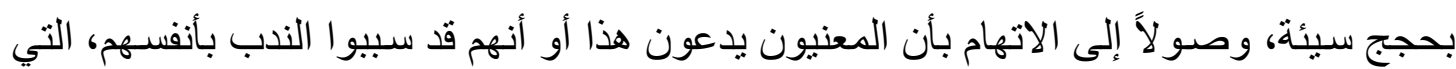
لا يستطيع أو لا يريد المرء تفسير ها بشكل مختلف.

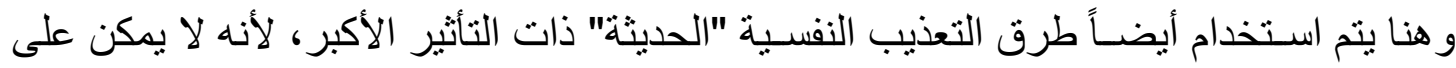

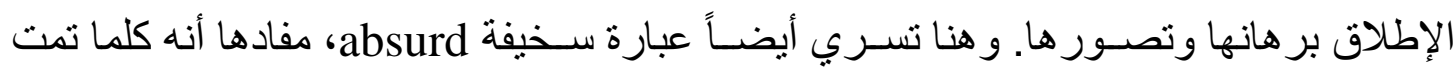

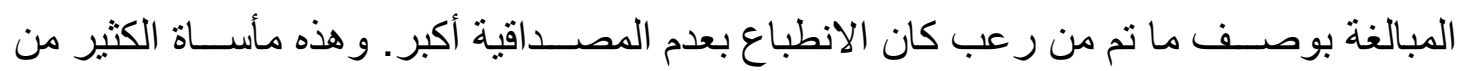
الضحايا و على هذا يعتمد الجلادون، حيث يتم اتهام الفرد هنا بالجنون.

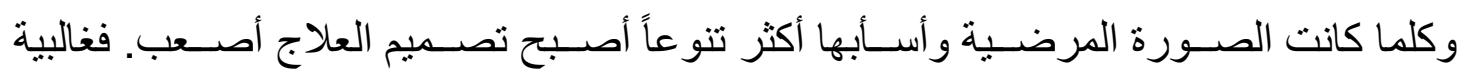

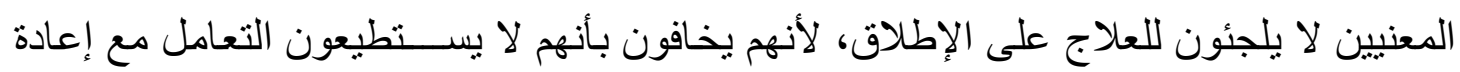

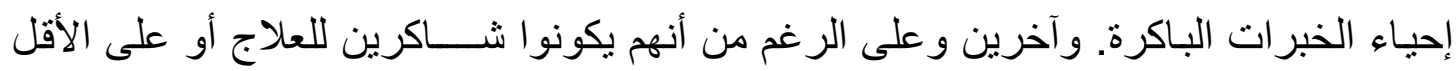

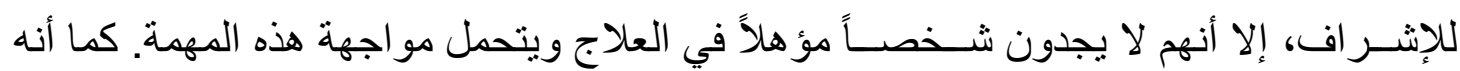
على المرء ألا ينسى بأن الثفاء مستحيل عملياً. و الهدف المنشود هو تخفيف المشكلات الروحية و الجسمية و الاجتماعية النفسية من أجل التمكن على الأقل من إدارة حياة ذات قيمة. لألئ.

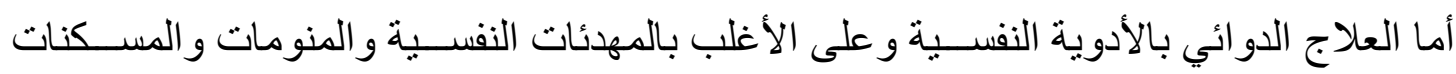

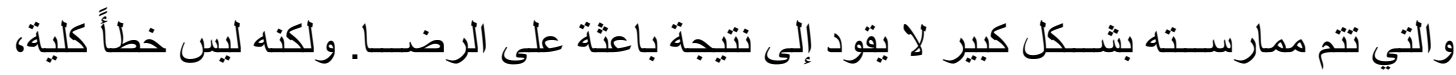

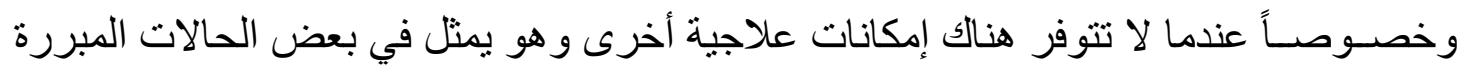

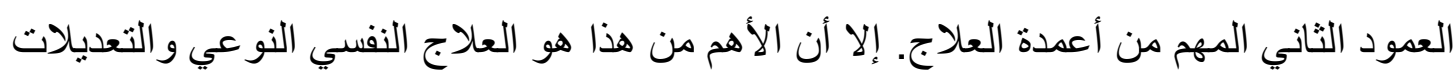

و المساعدات العلاجية الاجتماعية.

وسوف نقتصر هنا بالتطرق للمبادئ الأساسية للعلاج: ا - الإصغاء العارف، فيما يتعلق بالمشكلات الإنسانية؛ r- علاج القلق و الاضطر ابات المر افقة معه؛؛

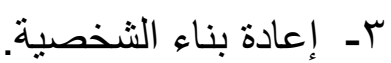

فوحدها حالة أن المريض المرتعب يعرف، بأن المعالج الخبير يعرف قصــــة معاناته وبثــــل خاص يعترف بها، أي يدرك أيضـاً العو اقب و العو اقب اللاحقة على أنها كذللك ويظل تحت دان دائماً موجوداً بالنسبة للمعني، و عندما يكون المعني على حافة احتياطاته أو موارده النفسية و الجسمية،

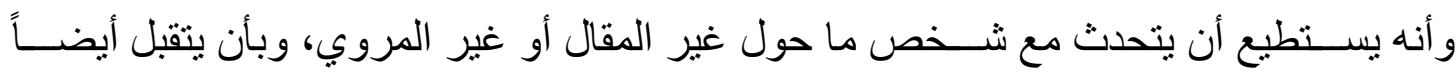


العو اقب اليومية الأخرى (البين إنسـانية و الزوجية والمهنية)، فإن ذلك يقدم نوعاً من الضــمان لرؤية وجود جدير بالإنسان على الأقل لبقية الحياة.

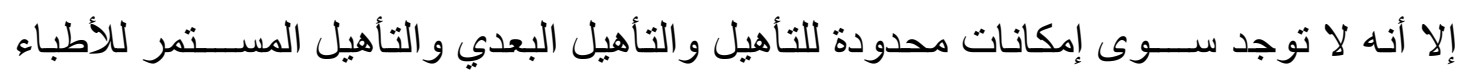

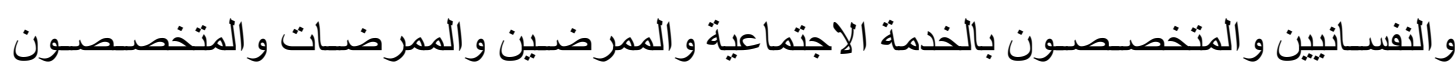
بالعلاج الفيزيائي و العلاج بالثغل. 